\title{
Investigating the source separation rate of municipal solid waste and economical and social determinance in Iran (2017)
}

\author{
J. Torkashvand ${ }^{1,2}$, MM. Emamjomeh ${ }^{3}, \underline{\text { M. Farzadkia }}^{1,2}$, R. Mahmodkhani ${ }^{4}$
}

\footnotetext{
${ }^{1}$ Department of Environmental Health Engineering, School of Public Health, Iran University of Medical Sciences, Tehran, Iran

${ }^{2}$ Research Center for Environmental Health Technology, School of Health, Iran university of Medical Sciences, Tehran, Iran

${ }^{3}$ Department of Environmental Health Engineering, School of Health, Qazvin University of Medical Sciences, Qazvin, Iran

${ }^{4}$ Islamic Azad University Tehran Medical Unit, Tehran, Iran

Corresponding Address: Mehdi Farzadkia, School of Health, Iran University of Medical Sciences, Shahid Hemmat Highway, Tehran

Tel: +98-21-86704820; Email: farzadkia.m@iums.ac.ir Received: 8 Aug 2018; Accepted: 11 Oct 2018
}

\section{Abstract}

Background: Municipal solid waste is a serious environmental issue in human societies. The source separation is a necessity for efficient municipal waste management (MSW).

Objective: The aim of this study was to evaluate the source separation rate of MSW in several Iranian cities, as well as to identify the determinance of the participation level in source separation. Methods: In this study, the source separation rate of waste in 12 cities of Iran was evaluated by information from waste management organizations and the economical and social determinance were reviewed. Data were analyzed by Excel.

Findings: In some cities, despite the coverage of about $90 \%$ of the training plans, the rate of source separation of MSW was less than $40 \%$, and the average of source separation for all studied cities was $13.46 \%$. The value of dry solid waste in all studied cities was estimated 705/000 tons per year which about $610 / 000$ tons are collected as the mix with other wastes. Awareness and education as the cultural factors and social trust, economic issues, and the continuity of the source separation plan as the social factors have been effective in people's participation in these projects.

Conclusion: Higher source separation rate in the wastes at the urban area requires consideration of all determinance in the planning and policy of WMS.

Keywords: Waste management, Recycling, Source separation, Solid waste

Citation: Torkashvand J, Emamjomeh MM, Farzadkia M, Mahmodkhani R. Investigating the source separation rate of municipal solid waste and economical and social determinance in Iran (2017). J Qazvin Univ Med Sci 2018; 22(5): 70-79. 


\title{
ميزان تفكيك از مبدأ در مديريت يسماند و مرورى بر عوامل اقتصادى و اجتماعى مؤثر بر آن در

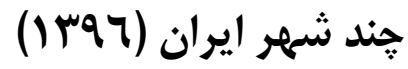

\author{
جواد تركاشوند او'،، دكتر محمدمهدى امام جمعه 'ب، دكتر مهدى فرزادكيا اوك، روحالله محمودخانىع
}

' كروه مهندسى بهداشت محيط دانشكده بهداشت دانشكاه علوم يزشكى و خدمات بهات بهداشتى - درمانى ايران، تهران، ايران

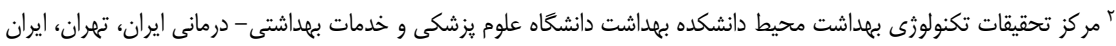

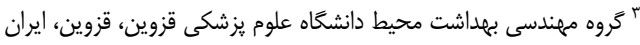

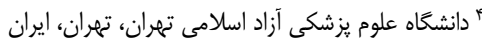

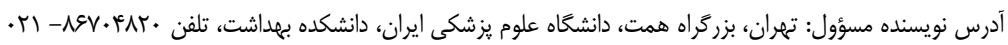
تاريخ دريافت: QV/V/P/IQ

زمينه: مديريت يسماند شهرى بهعنوان يكى مسئله جدى زيست محيطى در جوامع بشرى مطرح است. جمع آورى پِّماند بلهصورت تفكيك شـده از مبدأ يك ضرورت براى مديريت كاريت آمد يسماند است. هدف: اين مطالعه با هدف ارزيابى ميزان تفكيك از مبدأ پرّماند در جند شهر ايران و شناخت عوامل مؤثر بر ميزان مشاركت در طرحهاى تفكيك از مبدأ در مديريت پِماند خانگى انجام شد.

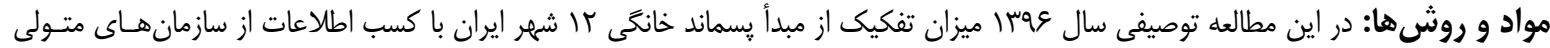

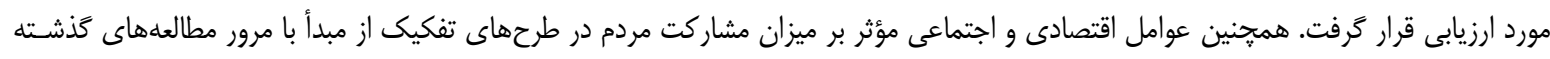

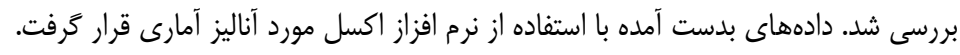

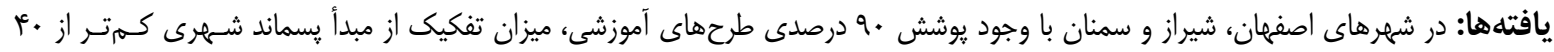

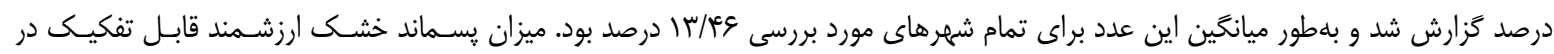

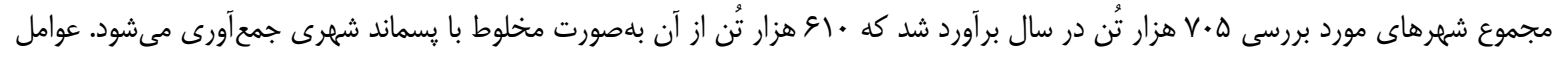

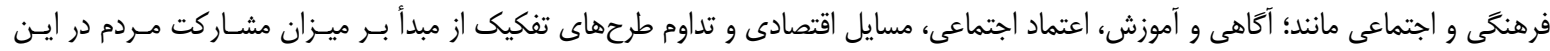
طرحها مؤثر شناخته شد.

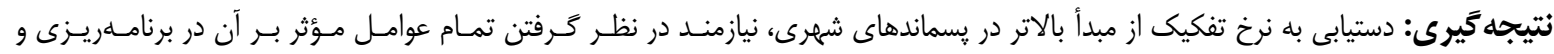
سياست گذارى مديريت يسماند است.

كليدوازهها: مديريت پِماند، بازيافت، تفكيك از مبدأ، بِماند خشك

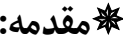

است. توسعه يايدار به توسعهاى كفته مىشود كـه از نظـر اقتصادى يويا، از لحاظ زيست محيطى غيرمخرب، از نظـر

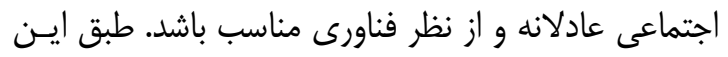
تعريف سيسته مديريت يسماند شهرى بايد بتواند در جهت

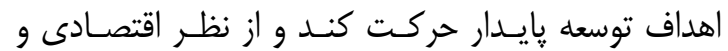

$$
\text { زيست محيطى قابل توجيه باشد.(r) }
$$

در دهلهاى اخير موضوعهاى زيست محيطى مـرتبط با توسعه اقتصادى براى كشورهاى در حال توسـعه بسـيار جذاب شده است و همزمان دولتها تلاش بيشترى براى برى

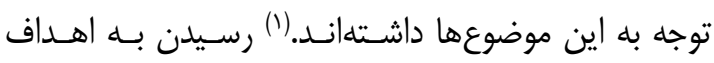

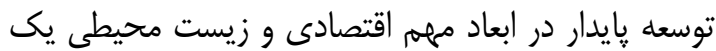
ضرورت اجتناب نايذير بــراى كشـورهاى در حـال توسـعه 
مشاركت در مـديريت يسـماند و ضـعف در اسـتانداردها و

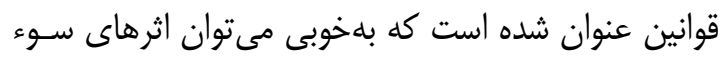

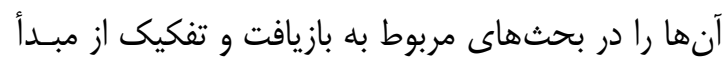

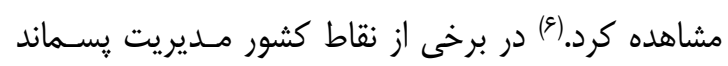
شهرى به لحاظ وضعيت اقليمى و جغرافيايى و مشـكلات

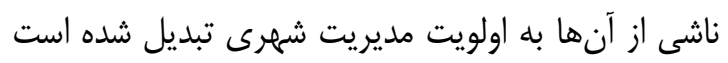

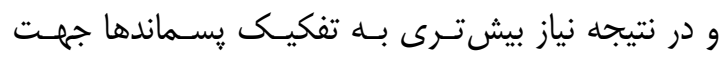

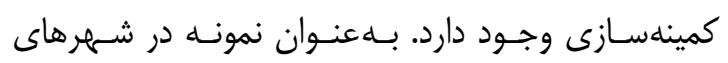

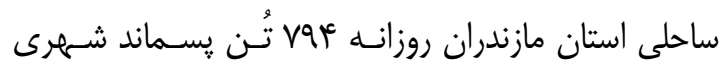

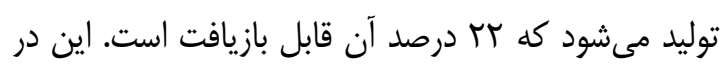

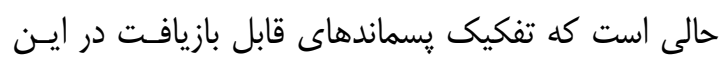

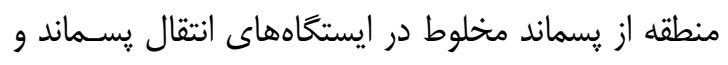

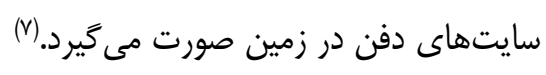

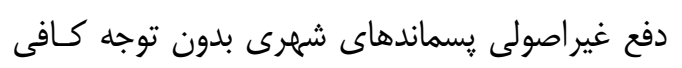

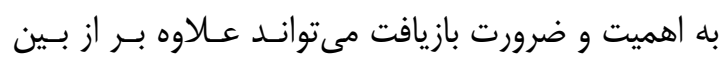

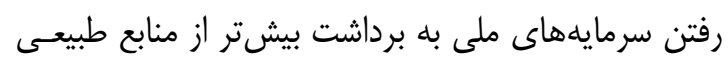

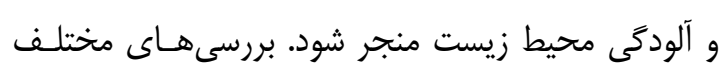

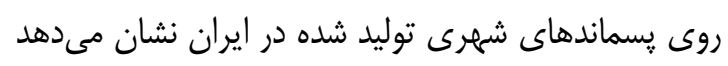

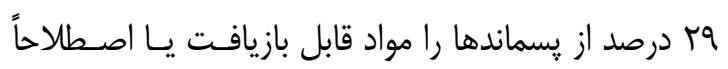

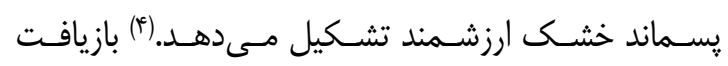
فرايندى است كه در هر يك از حلقههاى مديريت يسماند

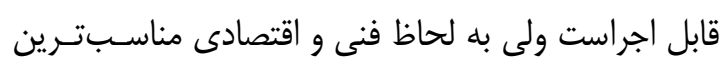
شيوه بازيافت بهرهگيرى از روش تفكيك يسماند در مبـدأ توليد است.(ه)

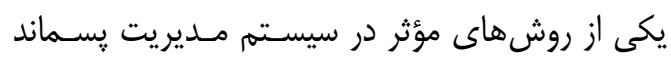

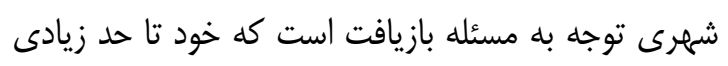

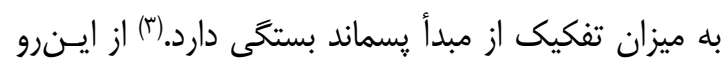

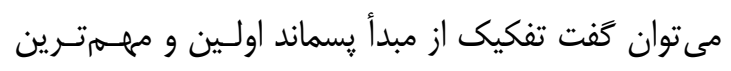

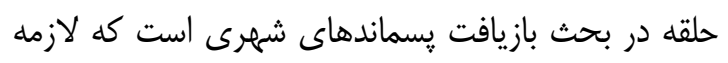
و اساس آن مشاركت مردم در طرحهاى تفكيـى از مبــــأ

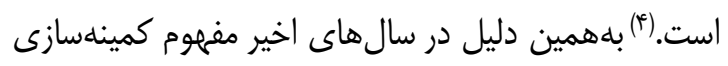

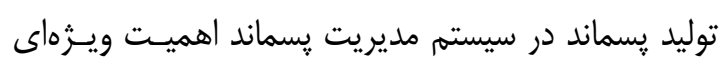

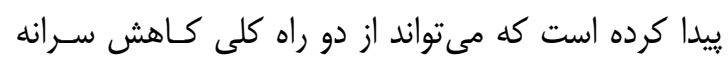

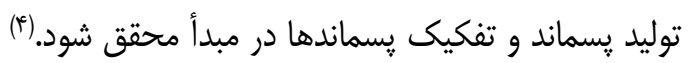

مديريت پِماندهاى جامد شهرى يك مسئله اساسى

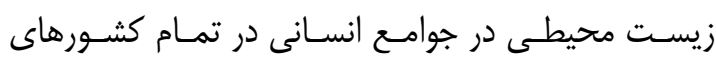

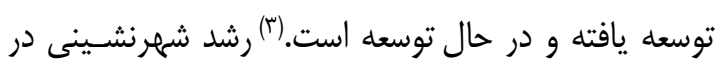
ايران و افزايش سطح رفاه و در نتيجه مصرف بيشتر كان كالا

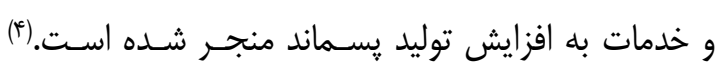

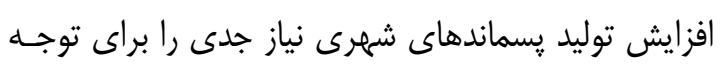

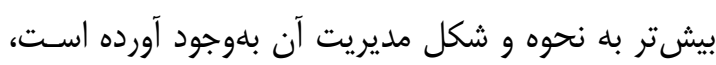

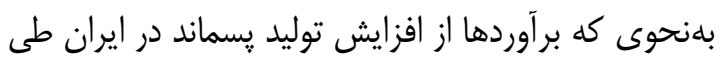

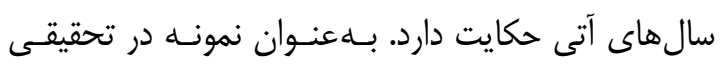

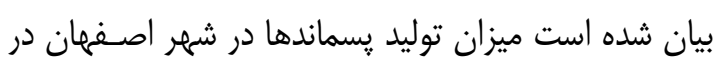

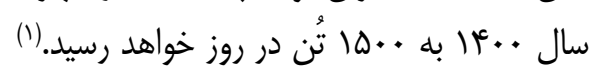

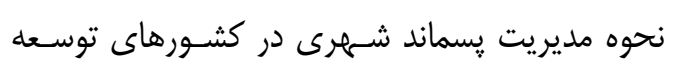

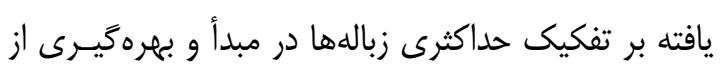

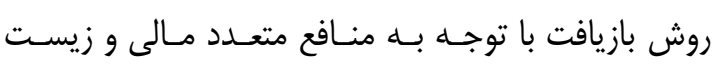

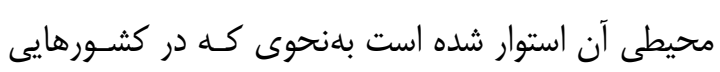

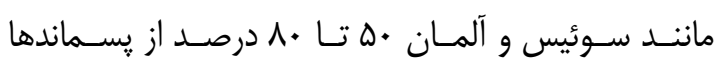

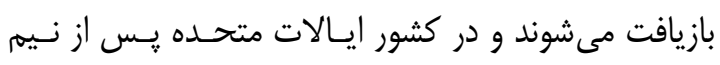

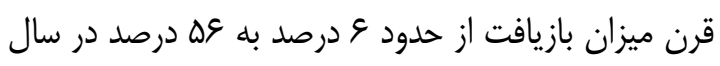

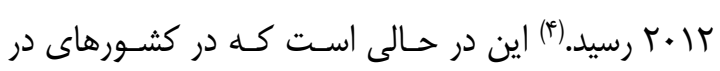

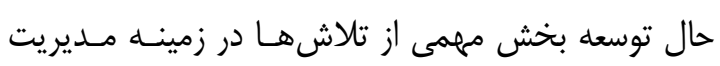

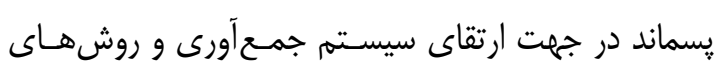

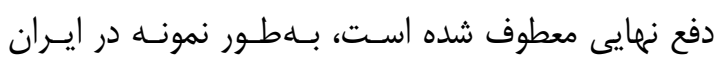

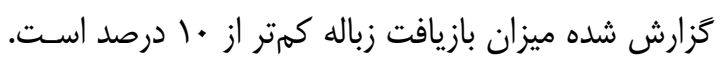

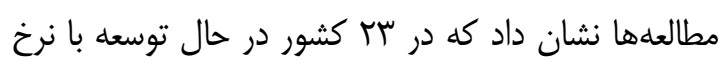

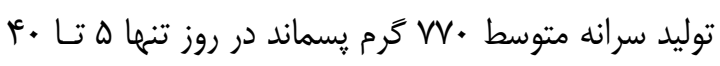

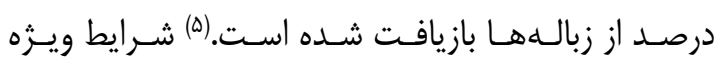
يسماندهاى شـهرى در ايــران و تفـاوت اقليمسى متفـاوت

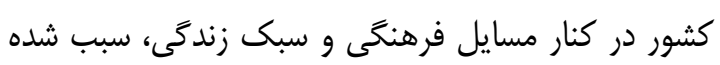
است مديريت پِماندهاى شهرى ايران با مديريت يسماند

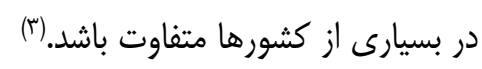
در تحقيقى در زاهدان، مرهمترين تهديـدهاى سيسـتم

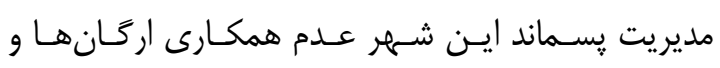

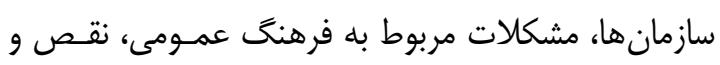

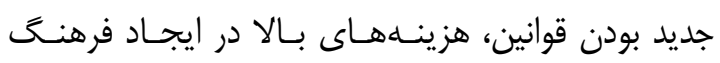




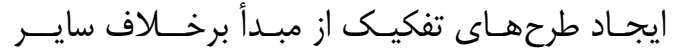
بخش هاى مديريت پِماند وابستخى جندانى به تكنولوزى إنى

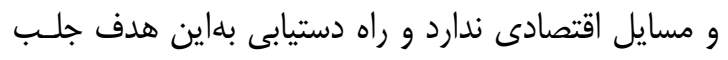

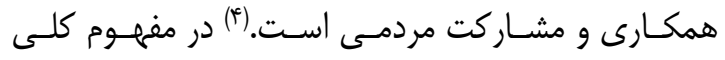

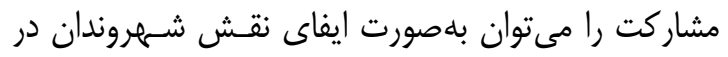

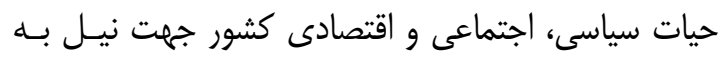

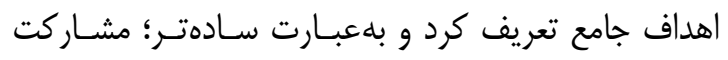

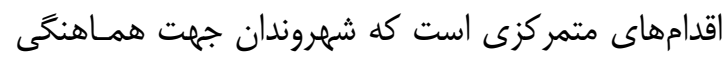

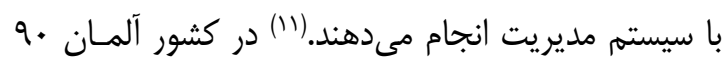

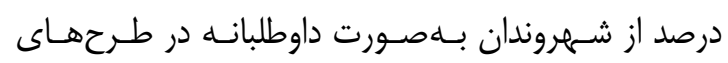

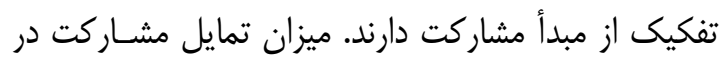

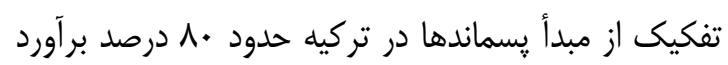

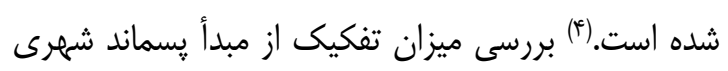

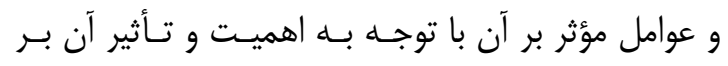

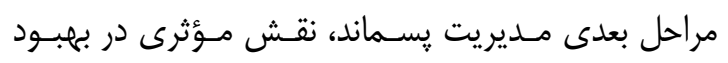

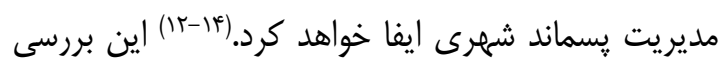
با هدف شناخت ميزان تفكيك از مبدأ در مديريت يسماند

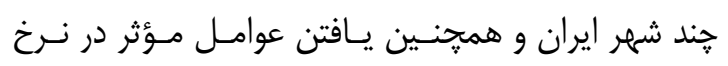

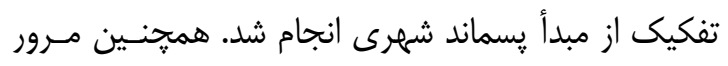
مطالعههاى كَذشته نيز براى بررسى عوامل مؤثر بر ميزان تفكيى از مبدأ پسماند شهرى انجام شد.

\section{مواد و روشها:}

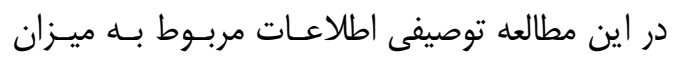

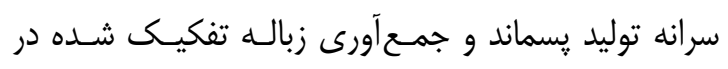

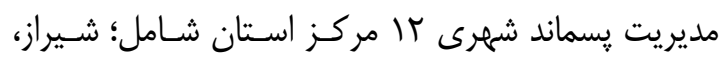

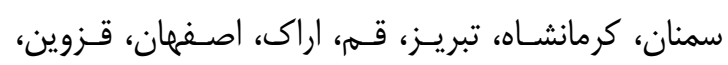

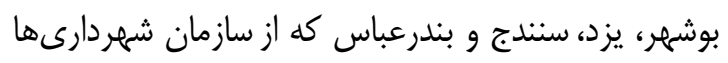

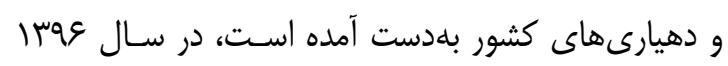

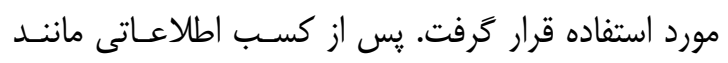

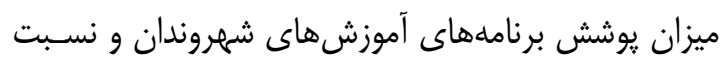
يسماند تفكيك شده از سازمان شهردارىها و دهيارى هـاى

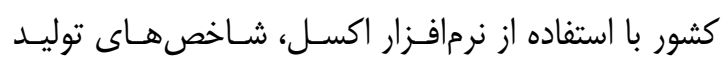

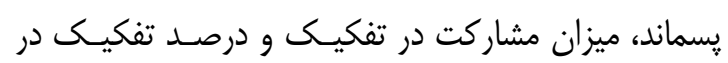

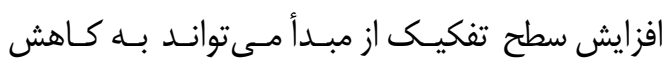

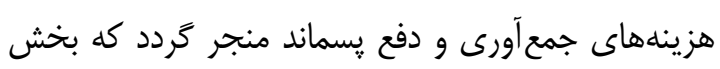

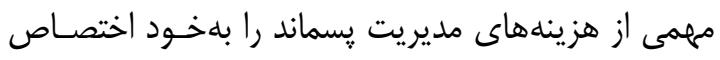

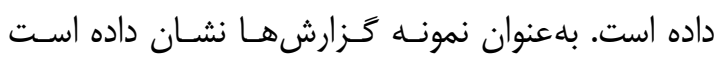

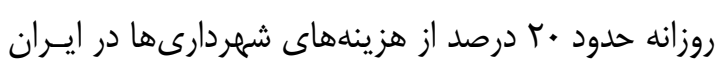

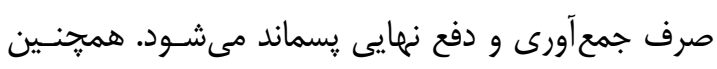

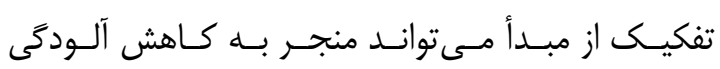

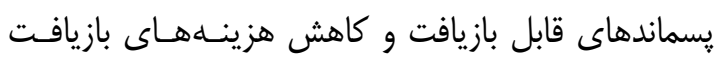

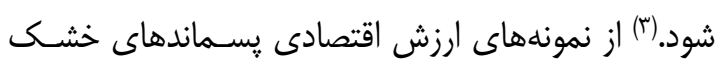

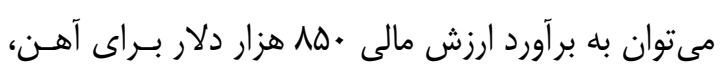

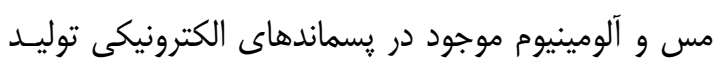

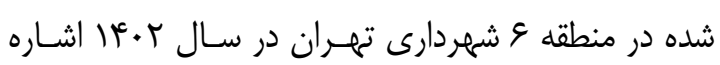

كرد. (1)

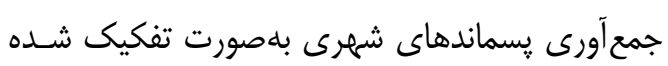

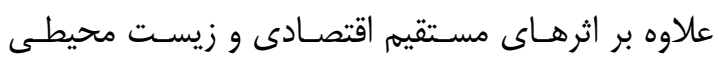

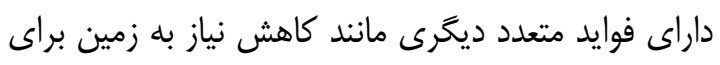

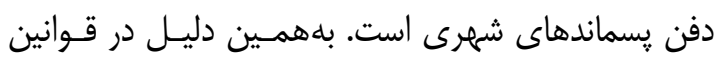

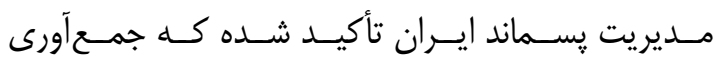

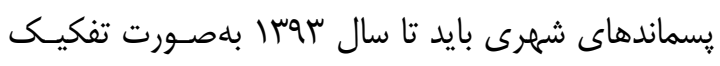

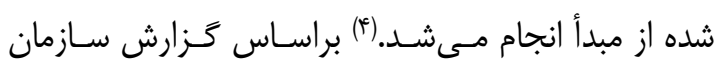

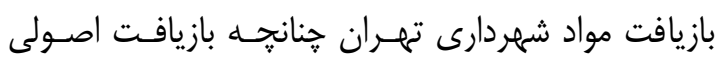

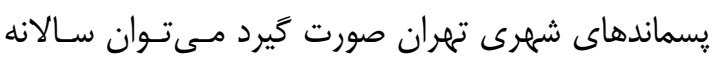

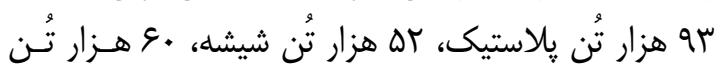

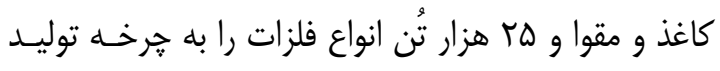

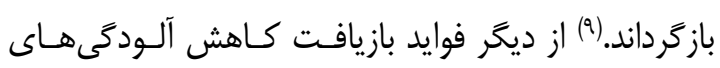

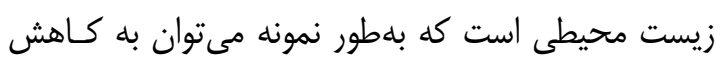

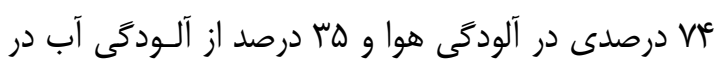

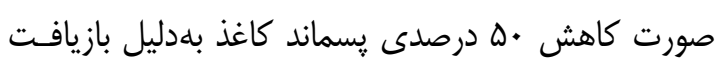

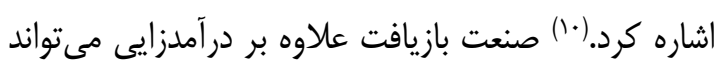

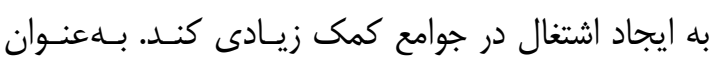

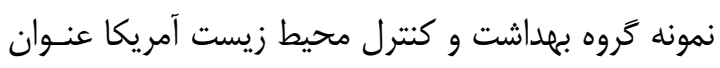
كرد در كاليفرنياى جنوبى صنعت بازيافت علاوه برد بر ايجـاد

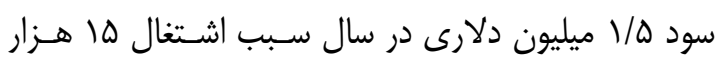
نفر شده است. نود ميليون 
(جدول و نمودار شماره ().) - (ج)

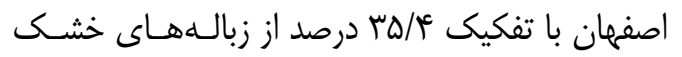

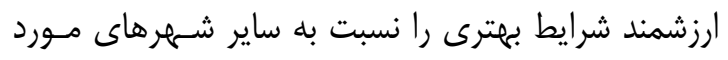

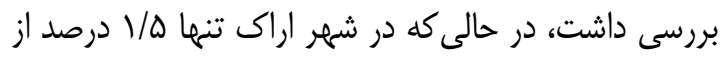

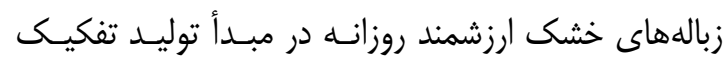

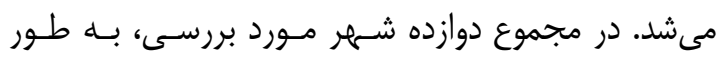

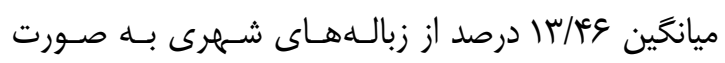

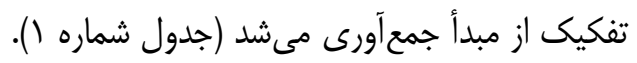

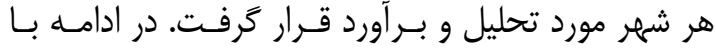

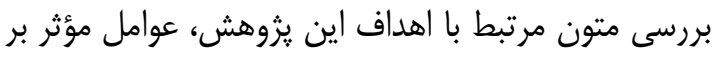

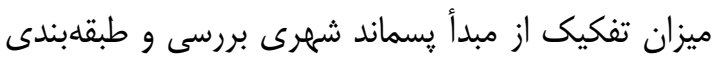
شد. - ميز

\section{(يافتهها:}

اين بررسى نشان داد در شهرهاى مورد تحقيق سرانه

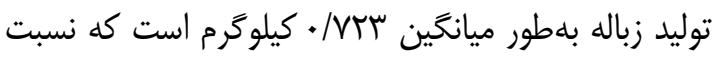
به يكى دهه كذشته به مقدار اندكى افز ايـش داشتـه اسـت

جدول ا - توليد و ميزان تفكيك از مبدأ يسماند در شهرهاى مورد بررسى

\begin{tabular}{|c|c|c|c|c|c|c|c|c|c|c|c|c|}
\hline بندرعباس & سندج & يزد & بوشهر & قزوين & اصفهان & اراك & قم & تبريز & كرمانشاه & سمنان & شيراز & شهر \\
\hline rsq & ro. & זו & iv. & rWr & lifr & ros & sv. & 11.4 & sa. & N & 990 & ميزان يسماند روزانه (تُن در روز) \\
\hline • / & . 94 &.$/ 94$ & $\cdot / \mathrm{AV}$ & $\cdot / \mathrm{rr}$ & .190 & .190 & ./AT & $\cdot / r$ & ./ve & $\cdot / \Delta S$ & .190 & سرانه روزانه بِسماند (كيلوكَرم) \\
\hline$\Delta / \tau$ & $\Gamma / \mu$ & $1 . / v$ & $11 / \mathrm{V}$ & $19 / 4$ & $r \Delta / \kappa^{\epsilon}$ & $1 / \Delta$ & $r / \Delta$ & 19 & $r / \Delta$ & r & $r T / 1$ & ميزان تفكيك زباله خشك ارز شمند (درصد) \\
\hline $\mathrm{v}$ & $8 \wedge$ & ra & ᄉ. & $r \Delta$ & 9. & $\Delta \Delta$ & 90 & r. & rv & q. & 9. & يوشش طرحهاى آموزش تفكيك در مبداً (درصد) \\
\hline
\end{tabular}

نمودار ا - ميزان زباله خشك ارزشمند و خشك ارزشمند تفكيك شده در شهرهاى مورد بررسى (تُن در روز)

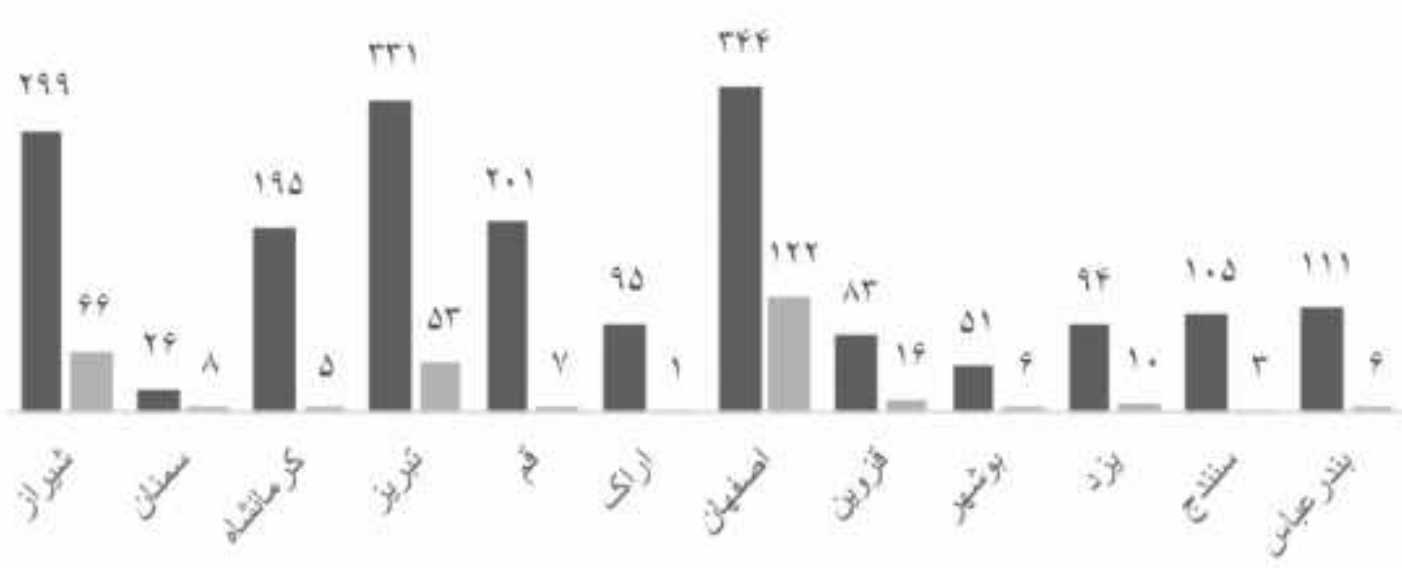

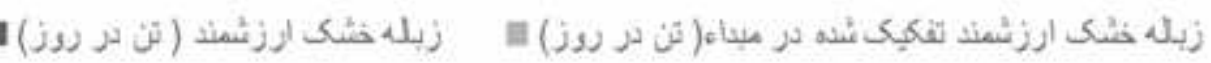


در شهر خرمآباد در سال عرب| نشان داد ميزان آكاهى در

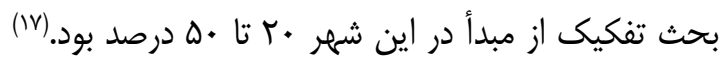

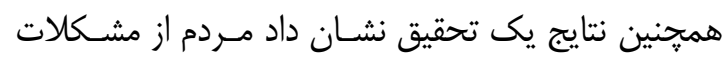

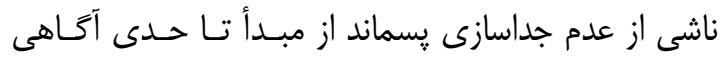

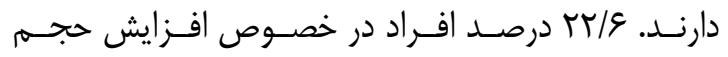

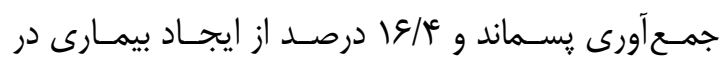

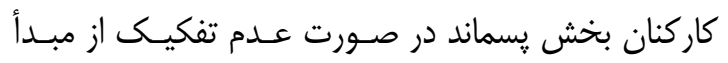

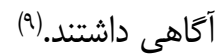

جدول r- ارتباط بين ميزان "آكاهى" و "تمايل و

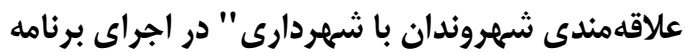
تفكيك از مبدأ(ع)

\begin{tabular}{|c|c|c|}
\hline $\begin{array}{c}\text { تمايل شهروندان به همكارى } \\
\text { (درصد) }\end{array}$ & 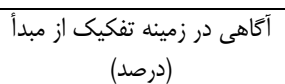 & آَكاهي \\
\hline$r$. & 10 & خيلى زياد \\
\hline f. & $r$. & زياد \\
\hline rq & ז4 & متوسط \\
\hline$i$ & 14 & م \\
\hline $\mathrm{V}$ & $\Lambda$ & خيلى كم \\
\hline
\end{tabular}

همجنين آموزش شهروندان بهعنوان يك عامل مهـمه مانه

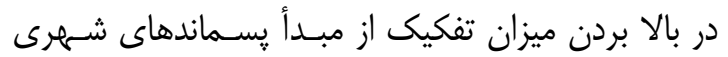

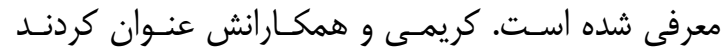

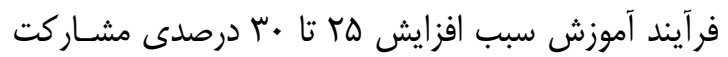

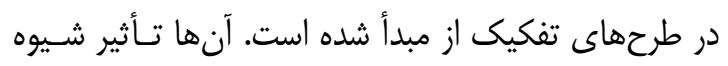

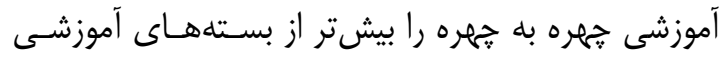

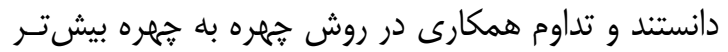

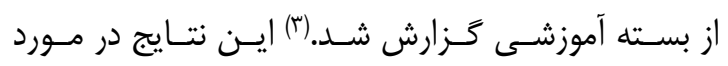

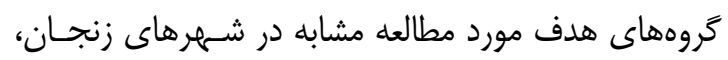

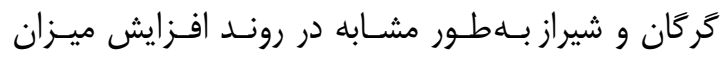

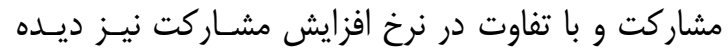

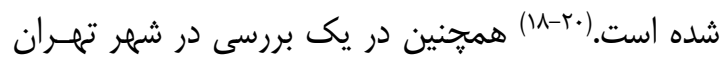
مشخص شد آموزش در دانش، بينش و كُنش شهروند درندان

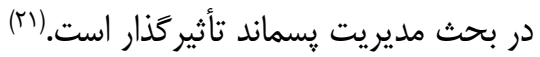
مطالعه حاضر مشخص كرد ميزان آموزش شمهروندان

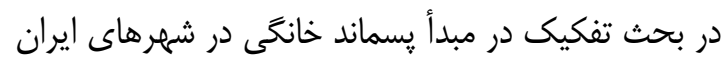

مرور مطالعهها نشان داد عوامل مؤثر بر ميزان تفكيك

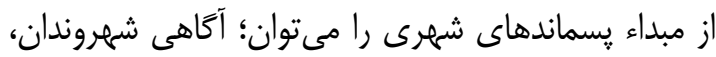

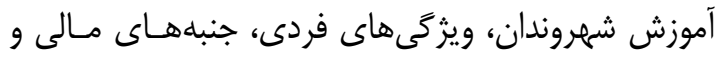

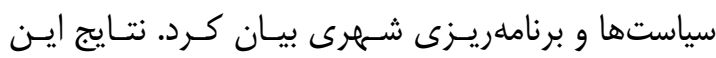
بررسى نشـان داد ميـزان مشـاركت در تفكيـى از مبــاء

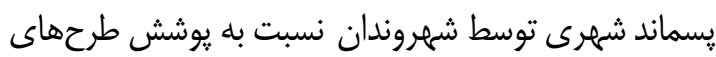
آموزش تفكيك در مبدأ در شهرهاى مورد بررسـى بسى بــيار

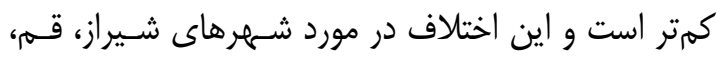

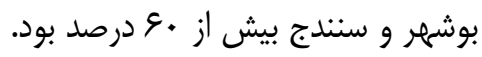

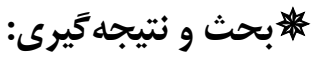

اين مطالعه مشخص كرد ميزان زباله تفكيك شده دهر در

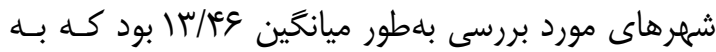

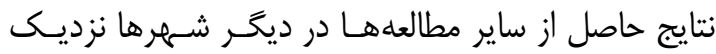

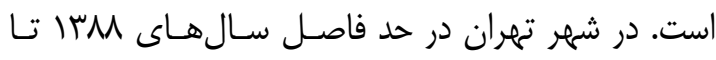
זوسا حدود ها درصد از يسماندهاى شهمرى بـهـهـورت

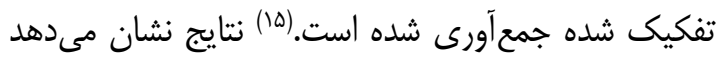

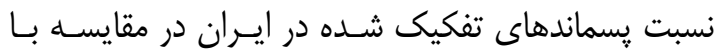

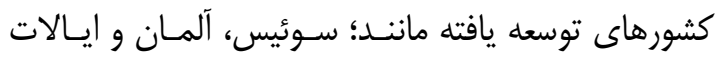

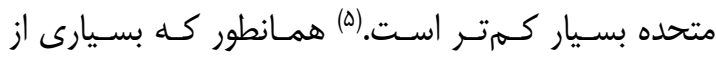
محققين عنوان كردهاند مهمترين بخش طرحهاى بران بازيافت

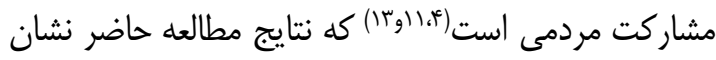
داد اين بخش در اغلب شهرهاى ايران بسيار ضعيف است و مانع افزايش مقدار كنونى سطح بازيافت در كشور خواهد

ميزان آَاهى مردم از فوايد تفكيـك از مبــأ يسـماند

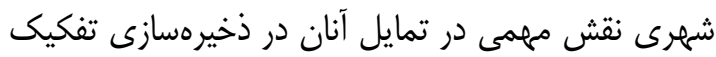

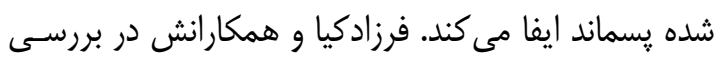

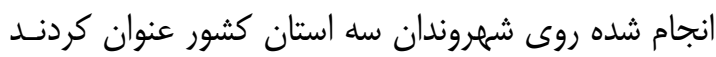

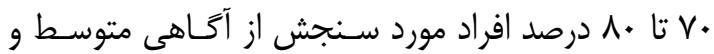

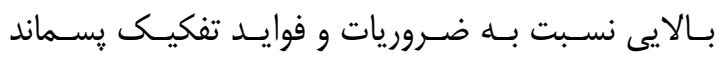

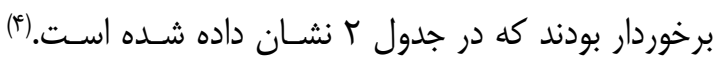
بررسى اين محققان با نتايج بهدست آمده توسط ملكوتيان در شهر كرمان تطابق كامل داشته است (19) ولى تحقيقها 


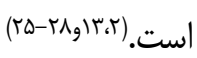

انخيزههاى مالى مىتواند در افزايش ميزان تفكيك از

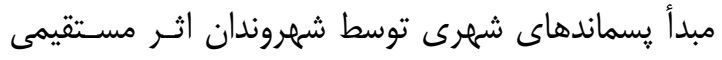

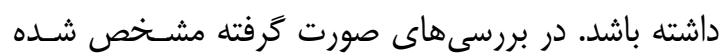

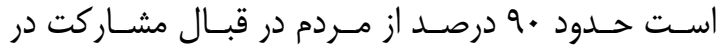
تفكيك از مبدأ پِماند داراى انتظاراتى مانند دريافت وجــهـ

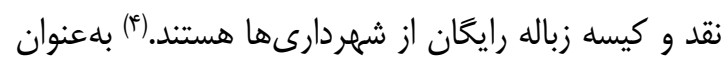

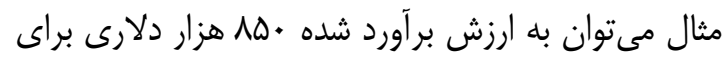

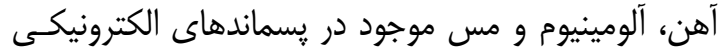
منطقه 9 شهردارى تهران در سـال r +. II اشـاره كـرد، در

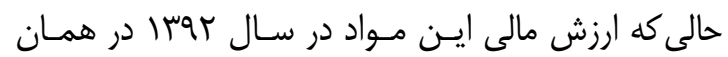

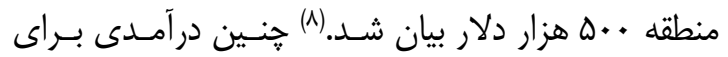
يك شهر از مهمترين ضرورتهاى انجام تفكيك از مبــــأ يسماندهاى شهرى از نظر حدود •V درصـد از شهمروندان

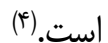

بررسى مالى درآمدهاى حاصل از طرحهـاى بازيافت

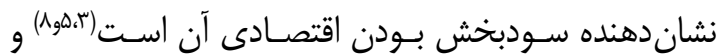

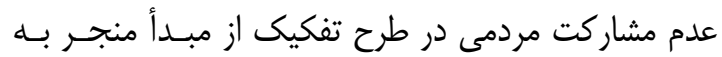

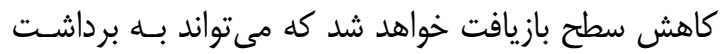

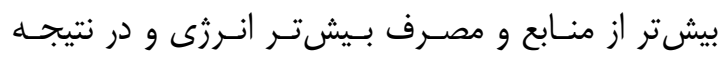

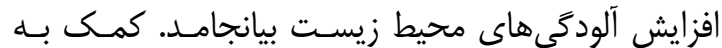
اجراى طرحهاى تفكيك از مبدأ توسط شهردارى، تـداوم

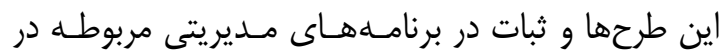

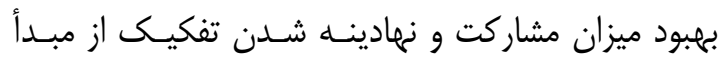

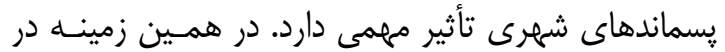
مطالعهاى در شهر تهران مشخص شد •V درصد از مـردم

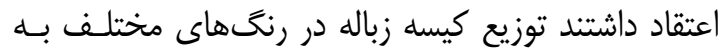
صورت رايعان در بين مردم سبب افزايش نرخ تفكيـى از

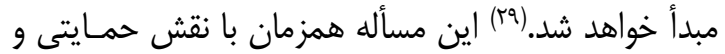
مديريتى شهردارى، مسايل مالى و توقع شهروندان را نيـز

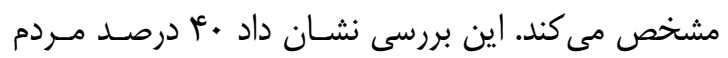

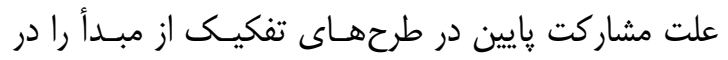
دسترس نبودن ظـروف تفكيـى زبالـه بـراى شـهروندان

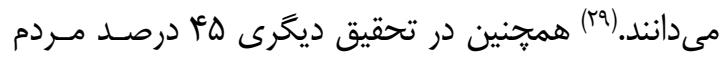

باطور ميانخين بالاست و يافتههـاى سـاير محققـان نيـز ميزان آكاهى و نكَرش شهروندان ايرانى را در مورد فوايـد

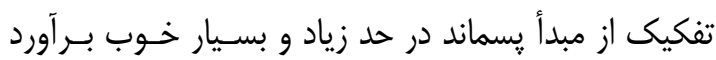

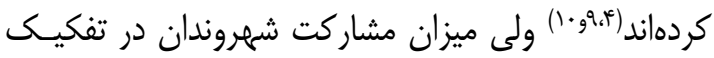

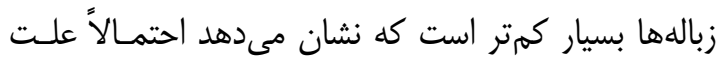

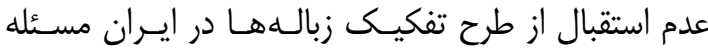

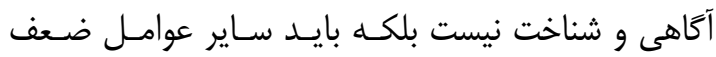

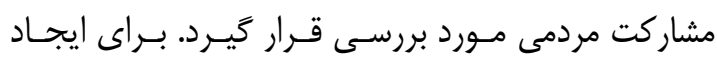

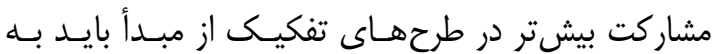

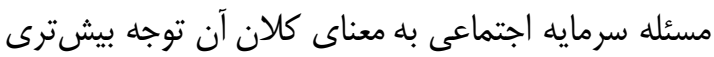

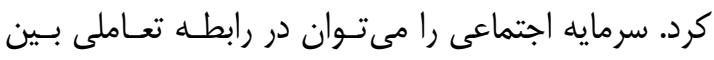

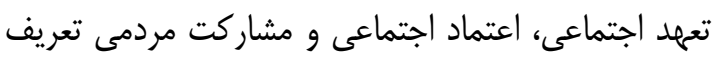

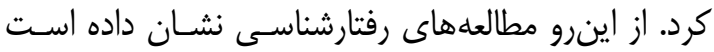

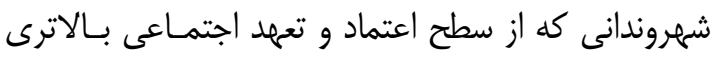

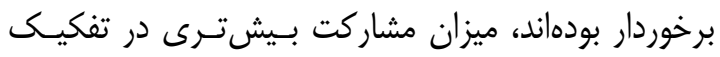
يسماندهاى شهرى از خود بروز دادهاند.(זا)

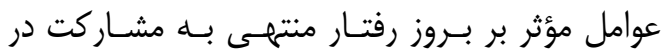

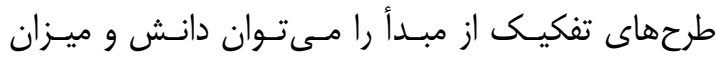

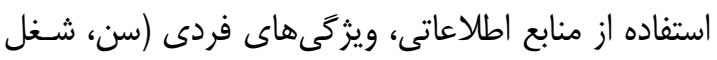

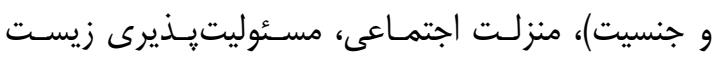
محيطى، ميزان رضايتمندى، انسجام، اعتماد و مشـاركت

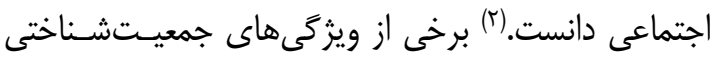

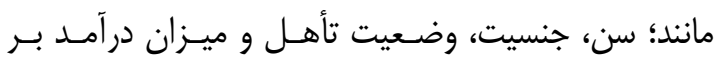

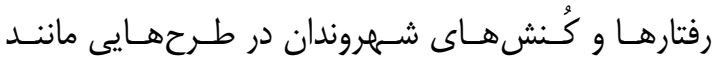
مشاركت در تفكيك از مبدأ يسماند مؤثر شناخته شدهانــــان.

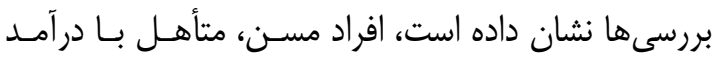

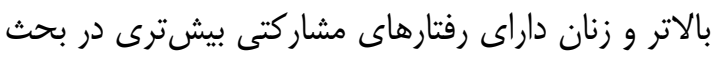

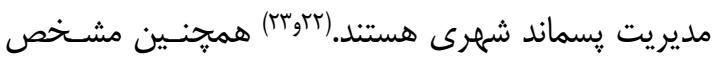
شده است كه افراد داراى بــدينى سياسـى نيـز مشـاركت كمترى در طرحهاى مديريت يسماند از خود نشـان مسى -

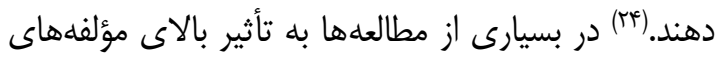

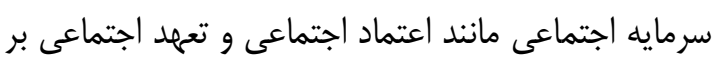

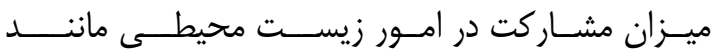

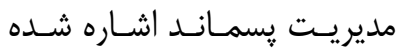




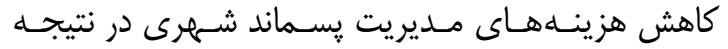

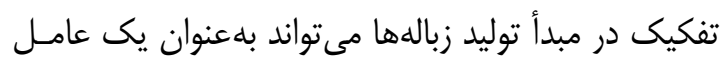

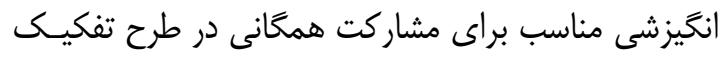

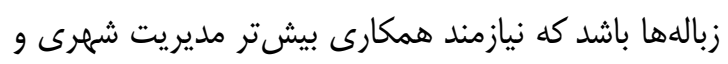

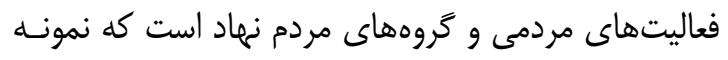

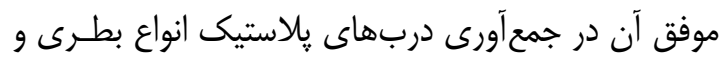

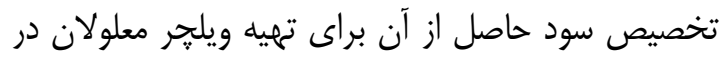

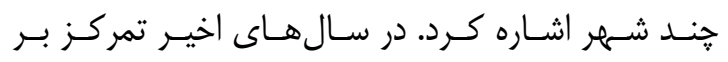

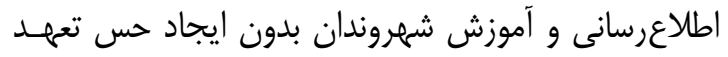

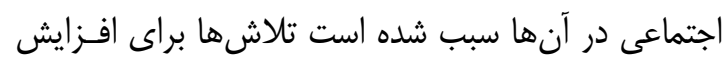

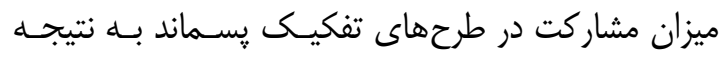

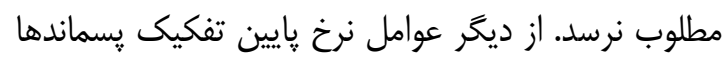

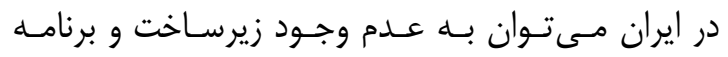

$$
\text { بلندمدت در اين خصوص اشاره كرد. }
$$

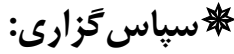

اين مطالعه حاصل بخشى از طرح تحقيقاتى به شماره F ايران مورد تصويب و حمايت مادى و معنوى قرار گرفت.

\section{:مراجع:}

1. Ebrahimi A, Ehrampoush MH, Hashemi H, Dehvari M. Predicting municipal solid waste generation through time series method (ARMA technique) and system dynamics modeling (Vensim software). Iran J Health Environ 2016; 9(1): 57-68. [In Persian]

2. Safari alamuti P, Shams A. Factors affecting the household waste prevention behavior of rural households in Qazvin county of Iran. Village and Development 2015; 18(1): 45-70. [In Persian]

3. Karimi J, Sadeghi M, Fadaie E, Mehdinejad MH. The effect of intervention through both face to face training and educational pamphlets on separation and recycling of solid waste in the Kalaleh City.
علت عدم موفقيت طرحهاى تفكيك از مبدأ را عـدم اجـرا يا بى نظمى در اجراى طرحهـاى تفكيـى از مبــــأ عنـوان كردهاند. (ז) تحقيقها نشان داده شهردارىها عملاً طـرح كارآمـدى

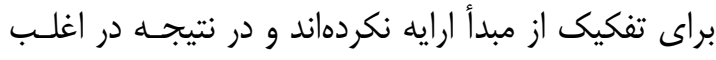

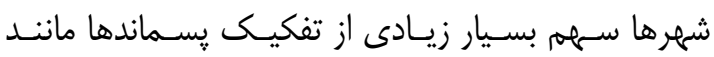

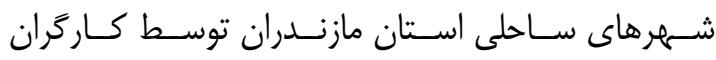

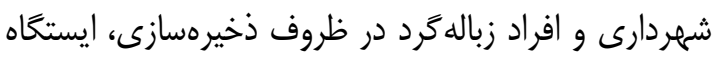

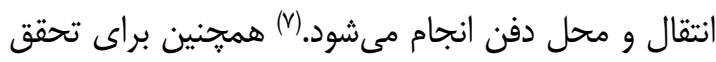

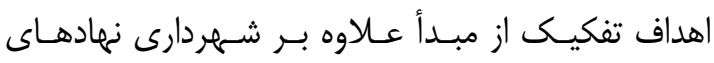

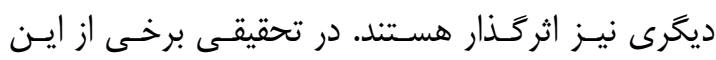

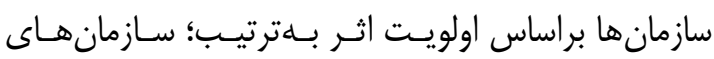

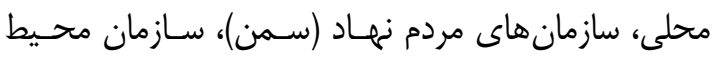

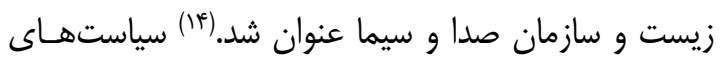

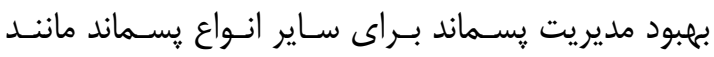

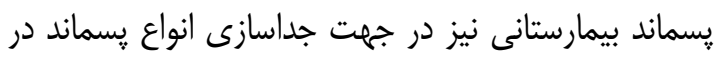

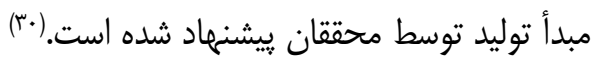

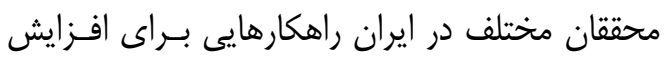

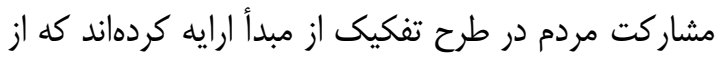

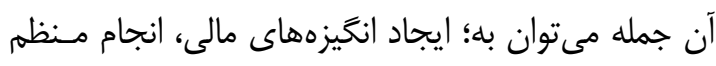

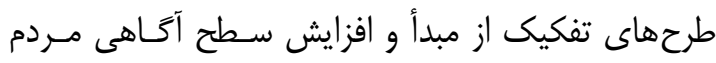

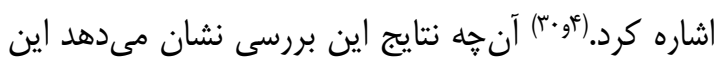

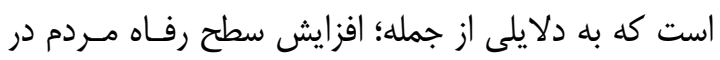

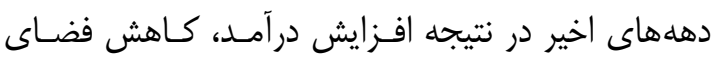

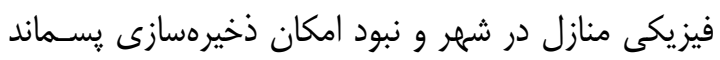

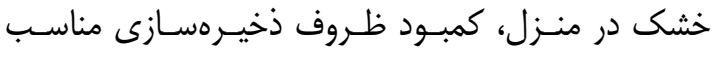

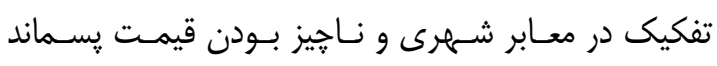

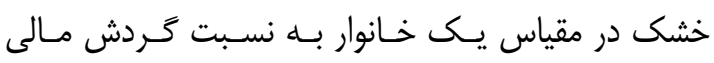

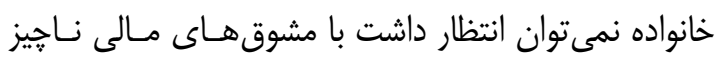

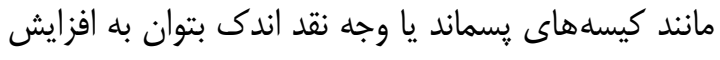
ميزان مشاركت مردمى در تفكيك زبالههاى خانكى دست نئن

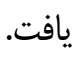
درآمدهاى بالاى حاصل از بازيافت زبالههـاى خشـى

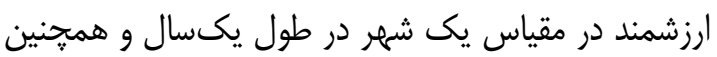


Iran J Health Environ 2015; 8(3): 275-84. [In Persian]

4. Fahiminia M, Farzadkia M, Nazari S, Jang SA, Matboo SA, Ibrahimi A, et al. Evaluation of the status of citizen participation in municipal waste source separation plan and offering corrective strategies. J Qom Univ Med Sci 2013; 7(5): 66-72. [In Persian]

5. Nazari A, Farzadkia M, Rastegar A, Ahmadi E. The 20 years view study_of dry waste recycling in Qom and it,s economic benefits. J Sabzevar Univ Med Sci 2014; 20(4): 530-8. [In Persian]

6. Rakhshani NHR, Safari K. Strategic planning management of solid waste in Zahedan city using SWOT method. J Environ Sci Technol 2016; 18(3): 149-64. [In Persian] 7. Abdoli M, Mehrdadi N, Razazadeh M. Coastal solid waste management in Mazandaran province. J Environmental Studies 2015; 40(4): 861-73. doi: 10.22059/ JES.2014.5300 3. [In Persian]

8. Hedayati aghmashhadi A, Jafary $\mathrm{H}$, Karami Sh, Golalizadeh S, Zahedi S. Economic valuation of recyclable metals of electronic wastes Case study: 6th district of Tehran. J Environmental Studies 2015; 40(4): 999-1009. [In Persian]

9. Ghanbari Q, Arshi S, Kamri M, SoroushZadeh M. Strategic factors of household solid waste segregation at source program, awareness and participation of citizens of the 3 municipality district of Tehran. Community Health 2015; 2(3): 149-56. [In Persian]

10. Abareshi A, Koochi S, Yaghoobi Far MA, Allahabadi A, Safari E, Zabihi M. A survey on patrons' awareness on domestic waste segregation in sabzevar health center 2014. Beyhagh 2016; 21(38): 28-36. [In Persian] 11. Khajeshahkohi A, Khoshfar Gh, Neghari
A. Evaluation of citizen participation scale in household waste management, (Case study: City of Mashhad). Geography Territorial Spatial Arrange 2015; 5(15): 215-32. doi: 10. 22111/GAIJ.201 5.2080. [In Persian]

12. Hassanvand M, Nabizadeh R, Heidari M. Municipal solid waste analysis in Iran. Iran J Health Environ 2008; 1(1): 9-18. [In Persian] 13. Haghighatian M, Gholipour K, Hashemianfar SA. A survey of the dimensions effect of social capital on municipal waste recycling in Shiraz. J Regional Planning 2016; 6(22): 83-96. [In Persian]

14. Afzali R, Hamzepour R, Karimi S, Pourahmad A. Investigate of extant laws and the performance agencies charge of the optimal management of urban wastes (case study: Tehran Metropolis). J Regional Planning 2017; 6(24): 101-14. [In Persian]

15. Hatami AM, Memarian fard M, Sabour MR. Evaluation of waste source separation in 22 districts of Tehran using GIS. J Geomatics Sci Technol 2017; 6(3): 63-74. [In Persian] 16. Malakootian M, Yaghmaean K. Evaluation of the knowledge, attitude and practice of residents of the city of Kerman to the municipal solid wastes management. J School Public Health Institute Public Health Res 2004; 2(4): 27-38. [In Persian]

17. Shams Khorramabadi GA, Porzaman HR. People involved in the management of municipal solid waste in 2005, in Khorramabad. J Lorestan Univ Med Sci 2006; 8(4): 23-8. [In Persian]

18. Norouzian Baghani A, Dehghani S, Farzadkia M, Delikhoon M, Emamjomeh MM. Comparative study of municipal solid waste generation and composition in Shiraz city (2014). J Qazvin Univ Med Sci 2017; 21(2): 57-65. [In Persian] 
19. Mehdinejad MH, Rajaei G, Aryaie M, Ahmadi M, Saeedinia RM. Awareness and performance of people of the cities of Gorgan, Gonbad, and Aliabad Katool (Iran) regarding management of municipal solid waste materials. J Mazandaran Univ Med Sci 2013; 23(106): 148-53. [In Persian]

20. Ghahremani M, Mohebi M, Najafi $\mathrm{H}$, editors. Knowledge of cooperation of the people in the recycling of household waste in Shiraz. 12th National Conference on Environmental Health 2009; Tehran. Iran

21. Keramatinezhad $\mathrm{H}$, Mazaheri $\mathrm{M}$. Assessing factors influencing the effectiveness of face to face training of Tehran citizens' behavior regarding urban waste management issues (Case study of $18^{\text {th }}$ zone of Tehran City). Urban Manage Studies 2013; 5(14): 49-64. [In Persian]

22. Bortoleto AP, Kurisu KH, Hanaki K. Model development for household waste prevention behavior. Waste Manage 2012; 32(12): 2195-207. doi: 10.1016/j.wasman. 2012.05.037.

23. Lee S, Paik HS. Korean household waste management and recycling behavior. Build and Environ 2011; 46(5): 1159-66. doi: 10.1016/j.buildenv.2010.12.005.

24. Swami V, Chamorro-Premuzic T, Snelgar R, Furnham A. Personality, individual differences, and demographic antecedents of self-reported household waste management behaviours. J Environ Psychol 2011; 31(1): 21-6. doi: 10.1016/j.jenvp.2010.08.001.
25. Grafton RQ, Knowles S. Social capital and national environmental performance. Australian National University, Economics and Environment Network Working Paper, EEN0206, Available at: http://een.anu.edu. au/. Updated in: 2003.

26. Nasrolahi Z, Eslami R. The study of the relationship between social capital and sustainable development in Iran (using Robert Foa model). J Economic Growth Dev Res 2014; 4(13): 61-78. [In Persian]

27. Salehi S, Emamgholi L. Effect of social capital on environmental behavior case study: Kurdistan province. Iranian Sociological Association 2013; 13(4): 90-115. [In Persian] 28. Aghili SM, Khoushfar Gh, Salehi S. Social capital and environmental responsible behaviors in the North of Iran (case study: Gilan, Mazandaran and Golestan provinces). J Agric Sci Natur Resour 2009; 16(1): 23650. [In Persian]

29. Kheyri Sh, Azad armaki A. Identify the factors affecting the adoption of waste management by the citizens of Tehran. Urban Manage Studies 2014; 6(17): 67-79. [In Persian]

30. Farzadkia M, Ansari A, Emamjomeh MM. Review of hospital waste management in one of the highly specialized hospitals. J Qazvin Univ Med Sci 2013; 16(4): 106-9. [In Persian] 